\title{
Crescimento do Eucalipto sob Efeito da Deriva de Glyphosate ${ }^{1}$
}

\author{
Eucalyptus Growth Under the Effect of Glyphosate Drift \\ TUFFI SANTOS, L.D. ${ }^{2}$, MACHADO, A.F.L. ${ }^{3}$, VIANA, R.G. ${ }^{3}$, FERREIRA, L.R. ${ }^{4}$, FERREIRA, F.A. ${ }^{4}$ e \\ SOUZA, G.V.R. ${ }^{5}$
}

\begin{abstract}
RESUMO - Um dos questionamentos no setor florestal é sobre os possíveis efeitos negativos da deriva de glyphosate sobre plantas de eucalipto ao longo de seu ciclo. Aos 30 dias após a aplicação (DAA) de $1.440 \mathrm{~g} \mathrm{ha}^{-1}$ de glyphosate, para controle de plantas daninhas em talhão de Eucalyptus grandis x E. urophylla (híbrido urograndis) com 120 dias após o transplantio, selecionaram-se 120 plantas ao acaso, que apresentavam graus de intoxicação variáveis. Os tratamentos foram os seguintes intervalos: 0-5, 6-10, 11-20, 21-30, 31-40 e 41-50\% de intoxicação das plantas, em que o intervalo de 0 - $5 \%$ foi considerado testemunha. Foram realizadas avaliações de altura e diâmetro, após a seleção das plantas, até os 360 DAA, sendo acompanhados durante esse período os sintomas de intoxicação. Aos 360 DAA, foi estimado o volume de madeira $\left(\mathrm{m}^{3}\right)$ e calculado o ganho em altura e diâmetro durante o período de avaliação. Plantas com intoxicação inicial acima de $31 \%$ apresentaram menor altura e diâmetro aos 360 DAA. O ganho em altura foi menor em plantas com intoxicação inicial acima de $41 \%$. Observou-se menor diâmetro a partir de $21 \%$ de intoxicação, com os menores valores de crescimento em diâmetro do caule observados em plantas com 41-50\% de intoxicação. Os danos causados pela deriva do glyphosate afetaram a produção de madeira aos 360 DAA, em que plantas com 21-30, 31-40 e 41-50\% de intoxicação apresentaram redução no volume de madeira de 18, 26 e 48\%, respectivamente, em relação à testemunha. Os resultados confirmam os prejuízos ocasionados pela deriva do glyphosate em plantas de eucalipto. Novas avaliações devem ser realizadas para acompanhamento do crescimento e desenvolvimento das plantas até o final do ciclo do eucalipto, a fim de elucidar os efeitos da deriva do glyphosate sobre a produção final da cultura.
\end{abstract}

Palavras-chave: produção de madeira, Eucalyptus ssp., controle químico, herbicida.

\begin{abstract}
The possible negative effects of glyphosate drift on eucalyptus plants throughout their cycle are one of the many issues faced in forestry. Thus, 120 plants presenting variable degrees of intoxication were randomly selected at day 30 after application of $1.440 \mathrm{~g} \mathrm{ha}^{-1}$ glyphosate, aiming to control the weeds in an area of Eucalyptus grandis $x$ E. Urophylla (urograndis hybrid) at 120 days after transplantation. The treatments were constituted by the following intervals: $0-5$; 6-10; 11-20; $21-30 ; 31-40$ and $41-50 \%$ of plant intoxication with $0-5 \%$ being considered the control treatment. Height and diameter were evaluated after plant selection, up to 360 days after application (DAA) and the intoxication symptoms were evaluated during this period. At $360 \mathrm{DAA}$ wood volume $\left(\mathrm{m}^{3}\right)$ was estimated and height and diameter gains were calculated. Plants with initial intoxication above $31 \%$ presented lesser height and diameter at 270 DAA Height gains were lesser in plants with initial intoxication above $41 \%$. Lesser diameter was observed from 21\% intoxication, with the plants with 41-50\% intoxication displaying the lesser values for diameter growth. The damage caused by the drift affected wood production at 270 DAA, with the plants with 21-30, 31-40 and 41-50\% intoxication being the ones presenting reduced wood volume of 18, 26 and 48\%, respectively, in relation to the control treatment. The results confirmed the damage caused by glyphosate drift to eucalyptus plants. However, new evaluations should be performed to monitor the growth and development of the plants until the end of their cycle so as to elucidate the drift effects on the final production.
\end{abstract}

Keywords: $\quad$ wood production, Eucalyptus ssp., chemical control, herbicide.

Recebido para publicação em 12.7.2006 e na forma revisada em 27.2.2007.

D.Sc. Bolsista de Pós-Doutorado em Fitotecnia, Universidade Federal de Viçosa - DFT/UFV, 36570-000, Viçosa-MG, $<$ ltuffi@yahoo.com.br>; ${ }^{3}$ Doutorando em Fitotecnia - DFT/UFV; ${ }^{4}$ Professor Associado - DFT/UFV; ${ }^{5}$ Mestre em Fitotecnia DFT/UFV. 


\section{INTRODUÇÃO}

O setor florestal no Brasil apresentou em 2005 uma expansão de 18\% em relação a 2004. Isso corresponde, segundo dados da Sociedade Brasileira de Silvicultura (SBS, 2005), a cerca de 550 mil hectares de florestas plantadas. O País possui, hoje, mais de 5 milhões de hectares de plantios florestais, sendo Minas Gerais o Estado com maior representatividade no negócio florestal brasileiro, em que o setor contribui, anualmente, com aproximadamente $\mathrm{R} \$ 420$ milhões para a receita estadual, gerando 163 mil empregos diretos e $644 \mathrm{mil}$ indiretos. Considerando os resultados de 2005, se o ritmo de crescimento persistir, o País estará afastando o risco de um "apagão florestal" (AMS, 2006).

A presença das plantas daninhas nos plantios florestais é considerada um dos maiores problemas na implantação, manutenção e reforma dos cultivos de eucalipto. Entre as justificativas para preocupação com o controle de plantas daninhas estão os prejuízos ao crescimento, causados pela competição por luz, nutrientes e água, e o fato de exercerem interferência de natureza alelopática, além de aumentar riscos de incêndio e dificultar os demais tratos silviculturais (Pitelli, 1987; Pitelli \& Marchi, 1991).

O glyphosate é um dos poucos ingredientes ativos registrados para a cultura, fato que, somado às características favoráveis desse produto, leva à ampla utilização desse herbicida no manejo de plantas daninhas em cultivos comerciais de eucalipto. O controle das plantas daninhas com glyphosate, em aplicações dirigidas, é intenso nos dois primeiros anos de implantação da cultura, podendo, em caso de reinfestação, estender-se por quase todo o ciclo por questões operacionais e busca de incrementos na produtividade.

O glyphosate é um herbicida não-seletivo, e sintomas de intoxicação em plantas de eucalipto por contato do produto com as folhas têm sido relatados com freqüência (Tuffi Santos et al., 2005a). Tais sintomas são caracterizados por cloroses foliares, evoluindo, em alguns casos, para necroses, enrolamento das folhas e superbrotação. O contato do glyphosate pode causar prejuízos ao crescimento do eucalipto ou mesmo a diminuição do estande, devido à morte de plantas mais jovens (Tuffi Santos et al., 2005a, b).

Existe carência de pesquisas voltadas para a elucidação dos efeitos da deriva do glyphosate sobre plantas de eucalipto ao longo de seu ciclo, principalmente sobre a produtividade da cultura. Essas informações são relevantes ao setor florestal, sendo de grande interesse dos produtores e das empresas florestais. Diante do exposto, objetivou-se avaliar os efeitos da deriva de glyphosate no crescimento e na produção de madeira de eucalipto.

\section{MATERIAL E MÉTODOS}

O experimento foi realizado em um plantio clonal de Eucalyptus grandis x E. urophylla (híbrido urograndis) no período de março de 2005 a abril de 2006. O talhão de eucalipto foi plantado em espaçamento de $3 \times 3 \mathrm{~m}$, em área de aproximadamente 2 hectares, no municipio de Senador Firmino-MG, em altitude média de $750 \mathrm{~m}$ e temperatura e índice pluviométrico com médias anuais de $21,9{ }^{\circ} \mathrm{C} \mathrm{e}$ $1.400 \mathrm{~mm}$, respectivamente.

A aplicação do glyphosate (1.440 g e.a. ha $\left.{ }^{-1}\right)$ foi feita por funcionários da fazenda, previamente treinados para controlar as plantas daninhas com volume de calda aplicado de $90 \mathrm{~L} \mathrm{ha}^{-1}$, aproximadamente. As plantas de eucalipto estavam com 120 dias após o transplantio e com altura média de 1,42 m. A aplicação do glyphosate foi feita com pulverizador costal munido de bico LA-1JC Yamaho (bico espuma coreano) e válvula reguladora de pressão (Jacto) de $300 \mathrm{kPa}$. Algumas plantas de eucalipto foram atingidas pela calda de aplicação, possibilitando a seleção de plantas, com graus de intoxicação variáveis, aos 30 dias após a aplicação (DAA). Os graus de intoxicação foram avaliados visualmente e separados em intervalos que constituíram seis tratamentos: $0-5,6-10,11-20,21-30,31-40$ e $41-50 \%$ de intoxicação das plantas; o intervalo de 0-5\% correspondeu à testemunha. Os tratamentos foram classificados de acordo com escala de notas de 0 a $100 \%$ de intoxicação (Frans, 1979), em que $0 \%$ corresponde à ausência de intoxicação e $100 \%$ à morte das plantas. Nessa escala a nota é atribuída de acordo com os sintomas de intoxicação por planta em relação 
à testemunha sem herbicida. Cada planta selecionada foi considerada como parcela experimental, sendo 20 repetições por tratamento.

Após seleção e enquadramento dentro dos diferentes intervalos de intoxicação, foram realizadas avaliações de altura (região do coleto até o ápice da planta), com uma baliza graduada, e do diâmetro das plantas a 1,30 m de altura (DAP) aos 45, 180, 270 e 360 DAA. Em todos os períodos de avaliação, foi acompanhada visualmente a evolução dos sintomas de intoxicação pelo glyphosate.

Com base na avaliação realizada aos 360 DAA, estimou-se o volume de madeira $\left(\mathrm{m}^{3}\right)$ e calculou-se o ganho em altura e diâmetro durante o período de avaliação. O cálculo do ganho em diâmetro e altura foi feito pela diferença entre a avaliação realizada aos 360 DAA e aquela feita aos 30 DAA.

Os dados foram submetidos à análise de variância e as médias comparadas pelo teste $t$ a $5 \%$ de probabilidade.

\section{RESULTADOS E DISCUSSÃO}

Sintomas visuais de intoxicação foram observados em avaliações realizadas até 180 dias após aplicação (DAA) do glyphosate (Figura 1). Na avaliação aos 270 DAA não se observaram, em todos os tratamentos, sintomas visuais de intoxicação das plantas. Esses sintomas, descritos aos 30 DAA do glyphosate, foram necroses e cloroses foliares nos ramos baixeiros do eucalipto. Plantas com maior intensidade de intoxicação apresentavam cloroses nos ápices caulinares.

Tuffi Santos et al. (2005a), trabalhando com simulação de deriva em eucalipto, observaram que o aparecimento dos sintomas se relaciona à quantidade de produto em contato com as plantas e que sintomas caracterizados por necroses e cloroses foliares eram observados já a partir do quinto dia após aplicação. Esses autores observaram recuperação, aos 45 DAA, das plantas tratadas com doses de 172,8 $\mathrm{g} \mathrm{ha}^{-1}$ de glyphosate, com emissão de novas brotações, porém com sintomas de intoxicação nas partes mais velhas. Neste estudo, observou-se recuperação das plantas que aos 270 DAA do glyphosate apresentavam ausência de sintomas de intoxicação.
Apesar da recuperação visual do eucalipto, plantas com porcentagem de intoxicação inicial acima de $31 \%$ apresentaram menor altura aos 360 DAA (Tabela 1), com ganho em altura inferior ao da testemunha. Entre os intervalos de intoxicação houve variação crescente na altura até os 180 DAA, com posterior diminuição das diferenças após essa avaliação (Figura 2). Esse comportamento indica a recuperação das plantas com porcentagem de intoxicação acima de $31 \%$.

O menor diâmetro ocorreu a partir de $21 \%$ de intoxicação; em plantas com 41-50\% de intoxicação foram observados os menores valores entre os tratamentos. O ganho em diâmetro de plantas com intoxicação inicial acima de $21 \%$ foi inferior ao observado na testemunha, com os menores valores de crescimento encontrados para essa variável em plantas com intoxicação acima de 41\% (Tabela 1).

Em conseqüência da altura e do diâmetro inferior, o volume de madeira foi influenciado pelo glyphosate, e plantas com intoxicação a partir de $21 \%$ tiveram crescimento volumétrico de madeira menor ao dos demais tratamentos. Plantas que aos 30 DAA tinham grau de intoxicação entre 41 e $50 \%$ foram as que apresentaram menores volumes de madeira (Tabela 1). Os intervalos de 21-30, 31-40 e 41$50 \%$ de intoxicação mostraram redução de 18 , 26 e 48\% do volume de madeira em relação à testemunha, respectivamente.

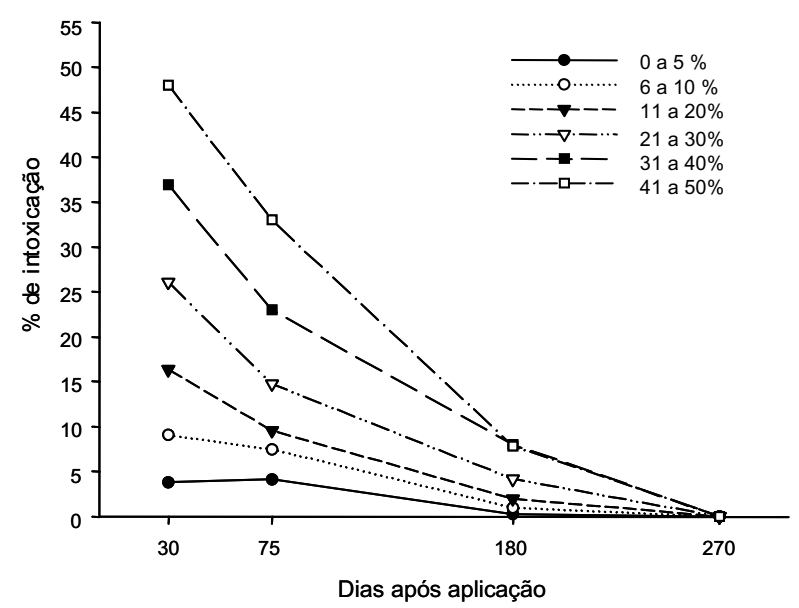

Figura 1 - Intoxicação pelo glyphosate em plantas de eucalipto em função do tempo após aplicação. Senador Firmino-MG, 2005/2006. 
Tabela 1 - Crescimento de plantas de eucalipto expostas à deriva de glyphosate aos 360 dias após aplicação. Senador Firmino-MG, 2005/2006

\begin{tabular}{|c|c|c|c|c|c|}
\hline $\begin{array}{c}\text { Graus de } \\
\text { intoxicação (\%) }\end{array}$ & $\begin{array}{c}\text { Altura } \\
(\mathrm{m})\end{array}$ & $\begin{array}{c}\text { Ganho em } \\
\text { altura }(\mathrm{m})\end{array}$ & $\begin{array}{c}\text { Diâmetro } \\
(\mathrm{cm})\end{array}$ & $\begin{array}{c}\text { Ganho em } \\
\text { diâmetro }(\mathrm{cm})\end{array}$ & $\begin{array}{c}\text { Volume } \\
\left(\mathrm{m}^{3} \text { por planta) }\right.\end{array}$ \\
\hline $0-5$ & $8,970 \mathrm{~A}$ & $7,321 \mathrm{~A}$ & $8,599 \mathrm{~A}$ & $6,106 \mathrm{~A}$ & $0,053 \mathrm{~A}$ \\
\hline $6-10$ & $8,960 \mathrm{~A}$ & $7,303 \mathrm{~A}$ & $8,520 \mathrm{~A}$ & $5,967 \mathrm{~A}$ & $0,051 \mathrm{~A}$ \\
\hline $11-20$ & $9,055 \mathrm{~A}$ & $7,339 \mathrm{~A}$ & $8,743 \mathrm{~A}$ & $6,112 \mathrm{~A}$ & $0,055 \mathrm{~A}$ \\
\hline $21-30$ & $8,660 \mathrm{AB}$ & $7,004 \mathrm{AB}$ & $8,040 \mathrm{~B}$ & $5,336 \mathrm{~B}$ & $0,044 \mathrm{~B}$ \\
\hline $31-40$ & $8,662 \mathrm{AB}$ & $7,167 \mathrm{AB}$ & $7,519 \mathrm{C}$ & $5,263 \mathrm{~B}$ & $0,039 \mathrm{C}$ \\
\hline $41-50$ & $8,420 \mathrm{~B}$ & $6,846 \mathrm{~B}$ & $6,767 \mathrm{D}$ & $4,491 \mathrm{C}$ & $0,031 \mathrm{D}$ \\
\hline DMS & 0,507 & 0,358 & 0,382 & 0,416 & 0,0054 \\
\hline CV $(\%)$ & 6,27 & 8,08 & 7,67 & 12,11 & 19,01 \\
\hline
\end{tabular}

Médias seguidas pela mesma letra na coluna não diferem entre si a 5\% de probabilidade pelo Teste t. Média de 20 plantas.

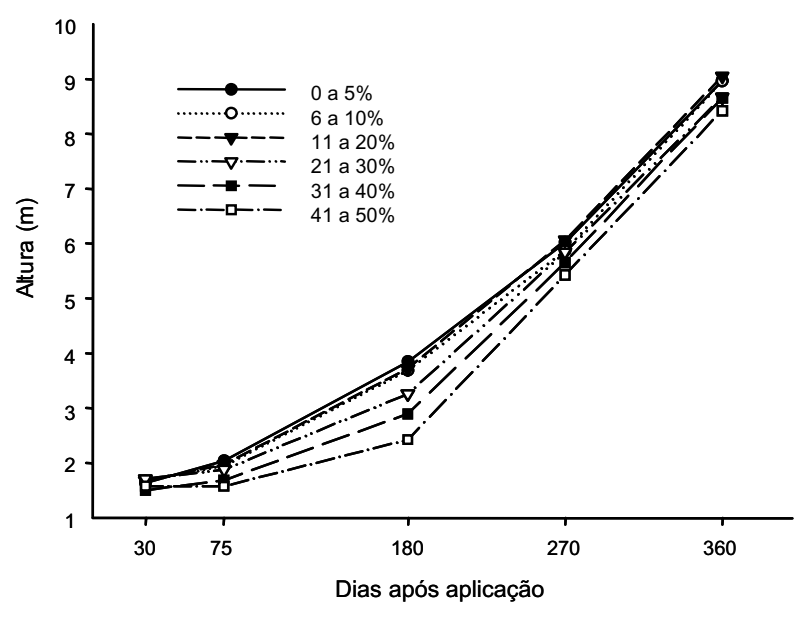

Figura 2 - Altura de plantas de eucalipto após a deriva de glyphosate em função do tempo após aplicação. Senador Firmino-MG, 2005/2006.

O glyphosate é um produto sistêmico, não-seletivo e altamente solúvel em água, e seu mecanismo de ação baseia-se na interrupção da rota do ácido chiquímico, responsável pela produção dos aminoácidos aromáticos fenilalanina, tirosina e triptofano, essenciais para a síntese protéica e divisão celular em regiões meristemáticas da planta (Cole et al., 1983; Foley et al., 1983; Bridges, 2003). O glyphosate causa distúrbios nas principais rotas metabólicas das plantas, levando à inanição (Hess, 2003). Desse modo, plantas de eucalipto em contato com o glyphosate apresentam seu crescimento comprometido, sendo a amplitude da redução do crescimento dependente da dose de glyphosate a que a planta foi submetida. A redução no crescimento do eucalipto exposto ao contato com glyphosate corrobora resultados encontrados em experimentos em casa de vegetação (Tuffi Santos et al., 2005a).

O comprometimento no crescimento do clone de eucalipto estudado foi constatado em plantas com intoxicação inicial acima de 21\%; entretanto, deve-se atentar para intoxicações inferiores, que podem ser prejudiciais em genótipos mais sensiveis ao glyphosate. A diferença de tolerância entre espécies (Tuffi Santos et al., 2006) e entre clones (Tuffi Santos et al., in press), pode ser usada na escolha de materiais genéticos a serem cultivados, constituindo-se em informação relevante para o manejo da cultura.

Entre as vantagens da homogeneidade obtida por plantios clonais de eucalipto estão a maior produtividade e melhor qualidade da madeira (Carvalho, 1994). Os danos causados pelo glyphosate na ocorrência de deriva, distribuidos em densidade variável dentro dos talhões de plantio clonal, provocam a heterogeneidade entre plantas, o que pode acarretar competição intraclonal desfavorável para plantas de eucalipto que tiveram seu crescimento inibido pelo herbicida. Adicionalmente, a qualidade da madeira, que tem sido uma das buscas dos programas de melhoramento genético, pode ser influenciada pelos efeitos do glyphosate, tendo em vista às alterações na produção de lignina em plantas tratadas com esse herbicida (Rizzardi et al., 2003). 
Os prejuízos da deriva do glyphosate sobre plantas de eucalipto reforçam a necessidade de cuidados quanto à tecnologia de aplicação em áreas de plantio dessa cultura , principalmente quanto ao treinamento dos aplicadores. Novas avaliações serão realizadas para acompanhamento do crescimento e desenvolvimento das plantas até o final do ciclo produtivo da cultura, visando o melhor entendimento dos efeitos do glyphosate sobre a produção e qualidade da madeira de eucalipto.

Aos 180 dias após a aplicação, os sintomas visuais de intoxicação por glyphosate não são mais perceptiveis no eucalipto. Plantas com intoxicação inicial acima de $21 \%$ tiveram crescimento inferior ao daquelas sem intoxicação. Por sua vez, plantas com intoxicação dentro dos intervalos de 6-10 e 11-20\% não tiveram seu crescimento reduzido pelo herbicida. Plantas com 21-30, 31-40 e 41-50\% de intoxicação apresentaram redução no volume de madeira, estimado aos 360 DAA, de 18, 26 e 48\% em relação à testemunha, respectivamente.

\section{LITERATURA CITADA}

ASSOCIAÇÃO MINEIRA DE SILVICULTURA - AMS. O balanço do setor florestal. <http://www.ams.org.br>. Acesso em: 10 abr. 2006.

CARVAlHO, P. L. P. T. Clonagem na Bahia Sul Celulose S.A. Piracicaba: IPEF, 1994. p. 25-27.

COLE, D. J.; CASELEY, J. C.; DODGE, A. D. Influence of glyphosate on selected plant process. Weed Res., v. 23, p. $173-183,1983$.

FOLEY, M. E. et al. Effect of glyphosate on protein and nucleic acid synthesis and ATP levels in common cocklebur (Xanthium pensylvanicum) root tissue. Weed Sci., v. 31, p. 76-80, 1983.
FRAS, R. E. Measuring plant response. In: WILKINSON, R. E. (Ed.). Research methods in weed science.

Melbourne: Southern Weed Science Society, 1972. p. 28-41.

BRIDGES, D. C. Mechanism of action of inhibitors of amino acid biosynthesis. In: Herbicide action course: an intensive course on the activity, selectivity, behavior and fate of herbicides in plants and soil. West Lafayette: Purdue University, 2003. p. 344-365.

PITELLI, R. A. Competição e controle de plantas daninhas em áreas agrícolas. IPEF, v. 4, n. 12, p. 25-35, 1987.

PITELLI, R. A.; MARCHI, S. R. Interferência das plantas invasoras nas áreas de reflorestamento. In: SEMINÁRIO TÉCNICO SOBRE PLANTAS DANINHAS E O USO DE HERBICIDAS EM REFLORESTAMENTO, 1., 1991, Rio de Janeiro. Anais... Rio de Janeiro: 1991. p. 110-123.

RIZZARDI, M. A. et al. Ação dos herbicidas sobre o mecanismo de defesa das plantas aos patógenos. Ci. Rural, v. 33, n. 5, p. 957-965, 2003.

SOCIEDADE BRASILEIRA DE SILVICULTURA - SBS. Dados estatísticos sobre a produção nacional de eucalipto. Disponível em: <http://www.sbs.org.br/secure/ estatisticas.htm>. Acesso em: 24 mar. 2005.

TUFFI SANTOS, L. D. et al. Crescimento e morfoanatomia foliar de eucalipto sob efeito de deriva do glyphosate. Planta Daninha, v. 23, n. 1, p. 133-142. 2005a.

TUFFI SANTOS, L. D. et al. Exsudação radicular do glyphosate por Brachiaria decumbens e seus efeitos em plantas de eucalipto e na respiração microbiana do solo. Planta Daninha, v. 23, n. 1, p. 143-152, 2005b.

TUFFI SANTOS, L .D. et al. Características da epiderme foliar de eucalipto e seu envolvimento com a tolerância ao glyphosate. Planta Daninha, v. 24, n. 3, p. 513-520, 2006.

TUFFI SANTOS, L. D. et al. Morphological responses of different eucalypt clones submitted to glyphosate drift. Environ. Exp. Bot., v. 59, p. 11-20, 2007. 